TEMPUS Revista en Historia General

Medellín, Colombia / enero-junio 2019 / Número 9

ISSN-e: $2422-2178$

Dossier en Historia Naval siglos XVI - XIX

\title{
LA PRESENCIA DE BUQUES DE \\ GUERRA Y SU IMPACTO EN LA \\ PENÍNSULA DE BAJA CALIFORNIA, \\ SIGLOS XIX-XX
}

\section{THE PRESENCE OF WARSHIPS AND THEIR IMPACT \\ IN THE PENINSULA OF BAJA CALIFORNIA, 19TH-20TH CENTURIES}

\author{
Dr. Francisco Alberto Núñez Tapia 1 (iD \\ Universidad Autónoma de Baja California (México)
}

\section{DOI: https://doi.org/10.17533/udea.tempus.n9a04}

Cómo citar este artículo en Chicago Manual of Style: Núñez Tapia, Francisco. "La presencia de buques de guerra y su impacto en la península de Baja California, siglos XIXXX”. Tempus Revista en Historia General no. 9 (2019): 121-145.

Artículo recibido el 31 de marzo y aprobado para su publicación el 4 de junio de 2019.

\footnotetext{
${ }^{1}$ Doctor en Historia por la Universidad Autónoma de Baja California. Miembro del Sistema Nacional de Investigadores, nivel 1. Correo: tapia.frank@gmail.com
} 


\title{
Resumen
}

La intervención de distintos buques militares en Baja California a causa de los movimientos filibusteros en la región detonó la especulación de una posible intervención extranjera en la península por la vía marítima, desde la segunda mitad del siglo XIX hasta las primeras décadas del XX, por ser la manera más práctica de tomar desprevenida a la población asentada en las costas y tener líneas de suministros seguras con el exterior. Por ello se debe analizar a fondo el papel que jugaron los buques durante estos conflictos armados en la península bajacaliforniana para conocer su verdadero impacto y evidenciar de esta manera la importancia del transporte marítimo en el desarrollo económico y social de la entidad al estudiar la historia marítima de Baja California.

Palabras Clave: Baja California, buques militares, filibusterismo, anexionismo, California.

\begin{abstract}
The intervention of different military ships in Baja California due to the filibuster movements in the region triggered the speculation of a possible foreign intervention in the peninsula by sea, from the second half of the 19th century to the first decades of the 20th, as the most practical way of taking over the population of the coast and securing supply lines with the outside. Therefore, the role played by military ships during these armed conflicts in the Baja California peninsula must be analyze in depth in order to know its true impact and thus demonstrate the importance of maritime transport in the economic and social development of the entity when studying maritime history of Baja California.
\end{abstract}

Key Words: Baja California, military ships, filibuster, annexationism, California. 


\section{Francisco Alberto Núñez Tapia}

\section{Introducción}

El presente artículo aborda los encuentros de distintos buques militares de bandera mexicana, estadounidense e inglesa en Baja California entre mediados del siglo XIX y principios del XX. Se analizan los sucesos que desencadenaron la llegada de buques de guerra al noroeste de la península bajacaliforniana donde describiremos el porqué de su presencia en territorio mexicano, así como el impacto que provocaron al presentarse en la región. La finalidad de este trabajo es evidenciar la importancia del estudio de las embarcaciones militares en la entidad y así propiciar futuras investigaciones que enriquezcan la historia marítima mexicana.

\section{Las incursiones del siglo XIX}

Al descubrirse yacimientos de oro en el norte de California en 1849, San Francisco se transformó, a partir de esta fecha, en la vía de acceso de muchos inmigrantes que llegaron a California en busca de este codiciado mineral. Con ellos, el crecimiento demográfico explotó y pasó de tener una población relativamente pequeña de 480 habitantes en 1848 , el a un poco más de 340,000 habitantes para $1900 .^{2} \mathrm{El}$ crecimiento demográfico siguió expandiéndose de norte a sur en California y la nueva población demandó distintos productos para subsistir y trabajar en las minas. Los puertos mexicanos de Mazatlán, Acapulco y San Blas en el Pacífico fueron los que aprovisionaron a estos hombres y familias en California y comerciaron con alimentos, ropa y aperos para animales de trabajo; así como con sarapes, cobijas, rebozos, mantillas, zapatos, botas, látigos, riendas, frenos, espuelas, correones, sillas de montar, alforjas, estribos, fustes de madera o galvanizados, sogas, y productos de consumo alimenticios entre otros artículos. ${ }^{3}$

Al establecerse un flujo constante de mercancías, el transporte marítimo se incrementó en los poblados costeros californianos y siguió aumentando por las olas de

\footnotetext{
${ }^{2}$ Karina Busto Ibarra, "El espacio del Pacífico mexicano: puertos, rutas, navegación y redes comerciales, 1848-1927", Tesis doctoral (México: El Colegio de México, 2008), 189.

${ }^{3}$ Ibarra, "El espacio del Pacífico mexicano: puertos, rutas, navegación y redes comerciales, 1848-1927", 217-223
} 
migrantes que hacían su recorrido hacia Estados Unidos, vía marítima. Fue debido al crecimiento demográfico que, comerciantes, mineros y empresarios de distintas nacionalidades, se interesaron por la península de Baja California, la cual, al estar despoblada y lejana de toda actividad comercial del resto de la República Mexicana, les resultó atractiva para propiciar el crecimiento comercial y poblacional californiano.

En la prensa de California de 1851, aparecieron los primeros anuncios sobre el interés de anexar la península bajacaliforniana a los Estados Unidos. Rafael Espinoza, jefe político del Territorio de Baja California en este periodo, informó al comandante general del estado de Sonora que había hombres interesados en llevar a cabo una invasión vía marítima. Espinoza armó a sus hombres debido a las noticias publicadas en la prensa californiana pero no se suscitó ningún suceso. La invasión se llevó a cabo dos años después cuando William Walker incursionó en la península con la finalidad de independizarla y anexarla a los Estados Unidos. ${ }^{4}$

Walker, quien era abogado de profesión, se interesó en establecer colonias civiles en el norte de México, en especial en Sonora, las cuales serían en verdad colonias militares. Zarpó de San Francisco rumbó a México en dos embarcaciones para Guaymas, el Arrow y Carolina. Al Carolina se le confiscaron cuando estaba a punto de zarpar de California hacia México 18 cajas de pólvora, 4 cascos de plomo de barras, casquillos, 300 libras de balas y un número de moldes. La noticia de la redada le sirvió a Walker para partir en la noche a bordo del Carolina y así evitar la detención; la embarcación zarpó hacia aguas mexicanas con varias decenas de hombres y ocho cañones de a seis. ${ }^{5}$

Las noticias de la incursión de Walker llegaron a manos de las autoridades mexicanas quienes prohibieron que él y sus hombres desembarcaran en Sonora y se le mandó capturar, pero el Carolina no llegó a Sonora sino al sur de la península de Baja California. Al arribar a este sitio, tomó el poblado de La Paz con 46 hombres y anunció

\footnotetext{
${ }^{4}$ Ángela Moyano Pahissa, "La invasión del filibustero William Walker", en Panorama Histórico de Baja California, coord. David Piñera Ramírez, (Tijuana: Universidad Autónoma de Baja California, 1983), 183-184.

${ }^{5}$ Miguel León-Portilla y José María Muría, Documentos para la Historia de Baja California, siglo XIX (México: Fundación Manuel Arango, 2009), 1:206.
} 


\section{Francisco Alberto Núñez Tapia}

que el territorio sería conocido como la República de Baja California, proclamándose Walker presidente de la misma y declarándola libre, soberana e independiente de México. Pero días después de su proclamación, Walker y sus hombres se retiraron hacia el norte de la península por enterarse sobre la presencia de un buque militar mexicano en la zona. ${ }^{6}$

En noviembre de 1853 desembarcaron en Ensenada de Todos Santos, ubicada en el noroeste de la península y tomaron una de las casas de la pequeña población como base la cual renombraron Fuerte McKibbin, en honor a uno compañero caído en el sur de la península. Walker mandó desde este sitio una carta a los ciudadanos de los Estados Unidos, fechada el 30 de noviembre donde narraba sus hechos:

El gobierno mexicano por mucho tiempo ha dejado de cumplir sus deberes hacia la Baja California. Ha cortado su territorio por el tratado de Guadalupe Hidalgo de toda comunicación directa con el resto de México y las autoridades centrales han mostrado poco interés en la península. La posición geográfica de la provincia la hace distinta de los intereses del resto de la República Mexicana. Pero, los lazos morales y sociales que la atan a México, han sido mucho más débiles y disolubles que físicos. Por ello, para desarrollar los recursos de California, y poder tener una debida organización social, era necesario hacerla independiente. La riqueza mineral y pastoral de Baja California es naturalmente grande, pero para desarrollarla es necesario tener un buen gobierno que de protección laboral y de propiedad. Bajo el gobierno mexicano, este territorio permanecería eternamente salvaje y sin cultivar, habitado por gente indolente y media civilizada deseosos de mantener fuera a todo extranjero de incursionar sobre los límites de su estado. México no ha realizado ningún tipo de labores gubernamentales para el pueblo de Baja California. No se han establecido medios de comunicación dentro de su territorio, o con el resto del mundo, ni se ha tomado la labor de protegerla de bandidos

\footnotetext{
${ }^{6}$ El Carolina desembarcó a 46 filibusteros al mando del Coronel Walker en el Cabo de San Lucas -que enseguida procedieron a La Paz y tomaron posesión de ese pueblo asegurando la persona del Gobernadore izaron su bandera y declararon la independencia de la Baja California. Después de cometer algunos robos y otros atentados, volvieron a embarcarse para la Ensenada de Todos Santos, a cien millas de San Diego donde han establecido su cuartel general. Allí parece que han llevado al extremo su osadía formando un gobierno bajo la presidencia del cabecilla Mr. Walker. Informe del vicecónsul de México, Barrón, donde relata las acciones de William Walker en La Paz, 215.
} 
que infestan el territorio. Es por ello, que ante el abandono en que se encuentra la península, México no debe quejarse si otros la toman y la hacen valiosa. ${ }^{7}$

Cuando Francisco Javier del Castillo Negrete, subjefe político del Territorio Norte de Baja California, se enteró de los sucesos acaecidos en Ensenada, mandó reunir a un grupo de hombres voluntarios para defender el territorio, ya que carecía de militares y armas. Uno de los que respondió el llamado del subjefe político fue Antonio María Melendres, habitante de un rancho contiguo a Ensenada, quien reunió a una partida de hombres armados y enfrentó en combate a Walker. Con el respaldo de los hombres que encabezaba Melendres lograron sitiar a los filibusteros establecidos en el Fuerte McKibbin haciéndolos huir a distintas partes del territorio hasta que se rindieron y salieron de mismo a mediados de $1854 .^{8}$

Algo que nos resulta interesante, de la intervención filibustera de Walker en Baja California, fue su pronta retirada de las costas del Pacífico. Suponemos que decidió alejarse de las costas por temor a que llegara algún buque de guerra mexicano y lo capturara fácilmente, razón por la cual huyó de La Paz como mencionamos anteriormente. El acceso más rápido a las poblaciones y asentamientos bajacalifornianos era indudablemente por vía marítima y por ello se apoyó en distintos navíos para llevar a cabo su faena como el Arrow y el bergantín Carolina, con el cual arribó a Cabo San Lucas para posteriormente tomar La Paz y Ensenada de Todos Santos. Pero, al no

\footnotetext{
${ }^{7}$ Para consultar la nota original completa, así como el estado mayor de Walker, véase "Address of President Walker, To the People of the United States", en Daily Alta California, vol. 4, no. 319, 8 de diciembre de 1853.

${ }^{8}$ En uno de los sitios al Fuerte McKiibin, Walker sorprendió a los hombres de Castillo Negrete y Melendres, los cuales se vieron forzados a replegarse momentáneamente. Debido a este suceso, y temiendo una inminente derrota, Castillo Negrete huyó hacia San Diego quedando Melendres al mando de los voluntarios y de la defensa del territorio. El 8 de marzo de 1854 llegó a La Paz el general José María Blancarte con 600 soldados del primer batallón ligero de línea. El presidente Antonio López de Santa Anna lo había nombrado comandante principal y jefe superior político de Baja California. Pero, debido a la distancia entre Ensenada y $\mathrm{La} \mathrm{Paz}$, y la falta de transportes rápidos, fue imposible auxiliar oportunamente a los voluntarios dirigidos por Melendres el cual, sin la ayuda de los hombres dirigidos por Blancarte, logró derrotar a Walker hasta expulsarlo del territorio. Como el subjefe político del partido norte abandonó su puesto después del descalabro que sufrió en Ensenada, Melendres, al terminar la lucha y por el importante papel que había desempeñado en los acontecimientos, quedó fungiendo como la autoridad, mientras el gobierno designaba a la persona que debía ejercerla. Adrián Valadez, Antonio Melendres (Ensenada: Reedición del Museo de Historia de Ensenada y la Sociedad de la Antigua California, 2015), 34.
} 


\section{Francisco Alberto Núñez Tapia}

recibir refuerzos, los cuales se especularon arribarían también por la vía marítima desde San Diego, se internó tierra adentro fracasando así su expedición.

Tiempo después de la fracasada invasión de Walker en Baja California, en las décadas de 1860 y 1870, nuevamente empezaron a circular noticias del interés del gobierno estadounidense por anexarse la península bajacaliforniana por encontrase casi totalmente despoblada y en cierto abandono por el gobierno mexicano; el objetivo principal eran los ricos yacimientos de minerales encontrados en toda la península.

Los comerciantes de California solicitaron al gobierno de los Estados Unidos la adquisición de la península bajacaliforniana para explotar los recursos minerales y naturales y así desarrollar la agricultura y la ganadería en esta zona. Este suceso alarmó a las autoridades mexicanas quienes optaron por enviar a José Matías Moreno a Baja California para que informara sobre las condiciones en las que se encontraba la península. Matías declaró que se tenía que establecerse un puerto de altura en Ensenada de Todos Santos para fomentar el comercio interior, impulsar la agricultura, minería y así incentivar la migración y el crecimiento demográfico con ello en la región. ${ }^{9}$

Fue hasta la década de 1880 que se cumplió la propuesta de Matías Moreno y Ensenada de Todos Santos empezó a funcionar como puerto de atraque y desembarque e incrementó el comercio vía marítima junto a la población local que creció cuando el puerto se transformó en la cabecera política del territorio norte desplazando a la antigua sede localizada en Real del Castillo. Con estos cambios, Ensenada se convirtió en el principal puerto del norte de la península situado en el Pacífico, resultado del constante comercio efectuado por transporte marítimo con California que servía como el principal medio para el desarrollo de la población y el puerto.

El desarrollo urbano en Ensenada fue posible gracias al establecimiento de compañías colonizadoras extranjeras en el puerto, las cuales tuvieron la posibilidad de invertir y explotar los recursos encontrados en la península. Se instalaron en el puerto para tener una mejor comunicación con el exterior debido a que el transporte marítimo era la vía más rápida y predilecta para llegar a la zona, así como sacar, por medio de

\footnotetext{
9 María Jesús Ruiz, “Aspectos económicos en el Partido Norte, 1849-1888”, en Baja California, un presente con historia, coord. Catalina Velázquez Morales, (Tijuana: UABC, 2002).
} 
distintas embarcaciones, los recursos naturales encontrados en las cercanías e introducir las mercancías y herramientas necesarias para el establecimiento de los colonos.

La primera compañía en establecerse fue La Compañía Internacional de México a finales de la década de 1880, manejada por inversionistas estadounidenses; la segunda llevó el nombre de Compañía Mexicana de Terrenos y Colonización a principios de la década 1890, manejada por ingleses. ${ }^{10}$ Ambas compañías pudieron desarrollarse en Ensenada gracias al proyecto colonizador impulsado por el gobierno de Porfirio Díaz el cual propiciaba la inmigración y colonización como eje político de modernización del país; el proyecto formó parte del impulso del gobierno porfirista derivado de la promulgación de las leyes de colonización en 1883. El puerto de Ensenada de Todos Santos se convirtió en la puerta de llegada de inmigrantes y mercancía, y a su vez, en la salida de diversos artículos manufacturados en la región, estableciéndose como el centro abastecedor de ranchos y distritos minerales de la zona fronteriza. ${ }^{11}$

Para 1886 el flujo de mercancías aumentó y el puerto ensenadense contó con una ruta de vapores los cuales atracaron regularmente durante sus recorridos semanales entre los distintos puertos mexicanos y californianos del Pacífico. Gracias a la llegada y salida de las embarcaciones, los habitantes de Ensenada pudieron comerciar, conocer los sucesos que se desarrollaban en ambas naciones y trasladarse a bordo de ellos, ya que la mayoría de los navíos operaron como barcos de carga y de pasajeros. ${ }^{12}$

Con el incremento demográfico e inversiones estadounidenses e inglesas en la zona, se elevó el número de navíos extranjeros en la región y fue común encontrar a buques militares nacionales y foráneos atracando en el puerto de Ensenada de Todos Santos. La presencia de estos buques militares fue principalmente para proteger las

\footnotetext{
${ }^{10}$ Para más información sobre estas compañías en Baja California véase David Piñera Ramírez, "Las compañías colonizadoras en Ensenada, 1886-1910", en Ensenada: Nuevas aportaciones para su historia (Mexicali: Universidad Autónoma de Baja California, 1999), 165-223; Hilarie J. Heath Constable, "La época de las grandes concesiones, 1883-1910", en Baja California, un presente con historia, coord. Catalina Velázquez Morales, (Tijuana: UABC, 2002).

${ }^{11}$ Francisco Alberto Núñez Tapia, "La industria del transporte marítimo y terrestre y el mercado fronterizo en el noroeste de la península de Baja California, 1882-1928", en Automotores y transporte público. Un acercamiento desde los estudios históricos, coords. Álvarez Palma e Ilse Angélica, (Zinacantepec, Estado de México: El Colegio Mexiquense, A.C., 2017), 40-41.

12 Tapia, "La industria del transporte marítimo y terrestre y el mercado fronterizo en el noroeste de la península de Baja California, 1882-1928”, 40-41.
} 


\section{Francisco Alberto Núñez Tapia}

inversiones extranjeras en la península pero además llevaron la encomienda de reportar las condiciones en que se encontraron los poblados asentados en la costa del Pacífico y del Golfo de California, sobre los sucesos y cambios en el país, suministrar a los lugareños de artículos y herramientas básicas, y servir como embarcaciones de pasaje para los funcionarios, militares y comerciantes de sus respectivas naciones radicados en la península. Asimismo, resguardaron el espacio marítimo bajacaliforniano de otros navíos foráneos que se dedicaron al contrabando de toda clase de recursos naturales encontrados en la península. Ejemplo de esto fueron los buques estadounidenses los cuales exploraron y realizaron levantamientos topográficos de las bahías, ensenadas e islas de Baja California, ${ }^{13}$ así como salvaguardaron las concesiones e inversiones de los colonos extranjeros de distintas nacionalidades establecidos en la zona.

Entre 1889 y 1890 la población asentada en las cercanías del poblado de Ensenada se dedicó principalmente a la explotación minera, agrícola, ganadera y manufacturera de distintos enseres. Los recursos explotados, así como los manufacturados, fueron enviados en su mayoría al sur de California debido a que en ese lugar se encontró su principal mercado. A consecuencia de esto, nuevamente los comerciantes de California solicitaron al Congreso de los Estados Unidos adquirir la península de Baja California argumentado que tenía un gran valor económico para el desarrollo de su nación y poco valor para México debido a su aislamiento con el resto del país. Al no tener respuesta positiva del gobierno estadounidense, se dio un nuevo intento de filibusterismo con la finalidad de segregar a la Baja California de México.

Al salir de la zona la Compañía Internacional de México en 1890, por cuestiones financieras, ingresó la Compañía Mexicana de Terrenos y Colonización, de capital inglés para continuar la colonización y comercio efectuado e iniciado en la península de Baja California por la compañía estadounidense e invirtieron y desarrollaron la minería, agricultura y manufacturas en la región. El establecimiento de la compañía colonizadora inglesa alarmó a los comerciantes y empresarios del sur de California y para tratar de obstaculizar su desarrollo en la región, empezaron a circular notas periodísticas en

\footnotetext{
${ }^{13}$ Vease G.W. Littlehales, The methods and results of the survey of the west coast of Lower California by the officers of the "U.S.S. Ranger" during the season of 1889 and 1890 (Washington, 1892).
} 
donde se informó que los ingleses deseaban segregar a la Baja California de México por sus propios intereses. En mayo de 1890 la prensa de San Diego y San Francisco denunciaron un posible movimiento filibustero en Baja California, liderado por un reportero de apellido Smith y capitalistas de San Diego quienes zarparían de los puertos californianos con la finalidad de tomar las poblaciones bajacalifornianas antes de que los ingleses lo hicieran. La conexión con los ingleses se daba por la figura de Buchanan Scott, director local de la Compañía Mexicana de Terrenos y Colonización, del cual se dijo que utilizaba a los conspiradores californianos para llevar a cabo su cometido y culpar a los estadounidenses. Para conocer mejor lo que estaba sucediendo en el noroeste de la península bajacaliforniana, el gobierno mexicano envío a Matías Romero, de la Legación Mexicana en Washington, para cerciorarse si los estadounidenses estaban detrás de un nuevo intento de filibusterismo o no. Romero concluyó que toda se trataba de conjeturas, suposiciones y algunos rumores de los cuales no había pruebas fidedignas. $^{14}$

Al ser absueltos de tales acusaciones, los ingleses, liderados por Edward Jenkins, presidente de la mesa directiva de la Compañía en Londres, informó que los verdaderos agitadores eran comerciantes de San Diego porque se oponían a que los ingleses colonizaran el norte la península de Baja California y harían todo lo posible por obstaculizar sus obras y detener a sus colonos quienes arribaban a San Diego para después proceder a Ensenada. ${ }^{15}$

Aun con estos obstáculos y tropiezos, la Compañía Inglesa, como se le conocía localmente, siguió operando en la península hasta la década de 1910, así como varios comerciantes estadounidenses establecidos en la zona. Es por ello que cuando estalló el movimiento revolucionario en México en 1910, aparecieron buques militares estadounidenses e ingleses con más frecuencia en la península. Su presencia generó

\footnotetext{
${ }^{14}$ Constable, "La época de las grandes concesiones, 1883-1910”, 280-281.

15 Véase Representante de la Compañía Mexicana de Terrenos y Colonización considera absurdas y calumniosas las acusaciones sobre el filibusterismo que se le atribuyen; el ministro plenipotenciario inglés afirma que sir Edward Jenkinson y el capitán Buchanan no pueden ser considerados sospechosos de tratar con filibusteros; el investigador Foster dice en su informe que la conspiración de San Diego ha sido una farsa en Miguel León-Portilla y José María Muría, Documentos para la Historia de Baja California, siglo XIX (México: Fundación Manuel Arango, 2009), 324-333.
} 


\section{Francisco Alberto Núñez Tapia}

rumores de una nueva y mayor invasión extranjera provocando así una tensión internacional como se describirá en el siguiente apartado.

\section{Los encuentros navales de 1911}

Al iniciar la Revolución Mexicana, a Baja California arribó un grupo de hombres armados procedentes en su mayoría de California sin identificarse o dar referencia de porqué habían ingresado a territorio mexicano, pero dado a que la mayoría eran estadounidenses, se especuló de un posible intento de invasión con fines de anexionar a Baja California a los Estados Unidos aprovechando la desestabilidad que se vivía en el país.

Cuando los estadounidenses tomaron el poblado fronterizo de Mexicali en enero de de 1911, la prensa de Los Ángeles, California, denominó a la partida de hombres como filibusteros donde se describió que los invasores intentarían tomar Ensenada (cabecera política de Baja California), para tener un puerto estable a través del cual operarían las expediciones filibusteras que llegarían desde California para unírseles en esta nueva expedición con fines anexionistas. ${ }^{16}$

Al difundirse la noticia que más hombres se uniría al grupo que había tomado Mexicali, la prensa californiana anunció que el 26 de febrero arribarían a Ensenada 150 combatientes con la finalidad de tomar el puerto. ${ }^{17}$ La noticia alarmó a los ensenadenses, ya había una amenaza real de que el poblado fuera tomado por un expedición filibustera llegada por la vía marítima.

El gobierno estadounidense negó haber autorizado la salida de hombres armados de su nación para intervenir de cualquier modo en el territorio mexicano el cual, estaba envuelto en un movimiento revolucionario a nivel nacional y mandó patrullar la costa del Pacífico en busca de estos voluntarios que querían zarpar hacia al el sur, con el fin de detenerlos.

\footnotetext{
${ }^{16}$ Lowell L. Blaisdell, La revolución del desierto Baja California, 1911 (México, Universidad Autónoma de Baja California, 2005), 103.

${ }^{17}$ Véase San Diego Union y San Diego Sun, febrero de 1911.
} 
Aun cuando los ensenadenses conocieron la anterior noticia, se alarmaron por el posible ataque estadounidense venido desde algunos de los puertos californianos, provocando una movilización social con el fin de proteger el territorio. La vigilancia en los puertos californianos fue estricta, pero aun así, siguieron saliendo embarcaciones hacia el norte y sur del Pacífico de estos lugares.

Tal caso fue el de Aurelio Sandoval, empresario mexicano residente de Los Ángeles, quien partió de San Diego hacia Ensenada en su yate el Yankee Girl el 27 de febrero de 1911.

Al día siguiente, 28 de febrero, algunos hombres del puerto al avistar el yate, dieron el grito de alarma que se trataba de filibusteros y la población de inmediato se preparó para defender el puerto. Los soldados, los rurales, así como una buena parte de los civiles, se alistaron para repeler el ataque de los supuestos invasores estadounidenses. Cuando distinguieron que se trataba de Aurelio Sandoval, conocido de la región y dueño de la concesión de la pesca en las aguas del Distrito, la calma regresó. ${ }^{18}$

La organización de la defensa del poblado, contra lo que resultó ser el yate de Sandoval, nos pone en perspectiva que de nuevo la población local estuvo dispuesta a tomar las armas contra una posible intervención extranjera llegada por la vía marítima como sucedió en 1853. El 28 de febrero la alarma resultó falsa, pero se comprobó valentía de la ciudadanía que, junto con los militares, estuvo dispuesta a defender y proteger la soberanía nacional de una posible invasión del país vecino del norte si fuere necesaria.

Mientras esto sucedía del lado del Pacífico, Mexicali seguía tomada debido a la pésima campaña militar por parte del jefe político del Distrito, el coronel Celso Vega, al cual le había sido imposible acabar rápidamente con estos "revoltosos", como él los llamó. Al mismo tiempo que sucedía la derrota de los bajacalifornianos, empezó a circular la noticia que llegarían al puerto de San Diego, California, buques de guerra que protegerían las inversiones estadounidenses en Baja California y, a su vez, de una

18 Marco Antonio Samaniego López, Nacionalismo y revolución: los acontecimientos de 1911 en Baja California (Tijuana: Universidad Autónoma de Baja California, 2008), 271. 


\section{Francisco Alberto Núñez Tapia}

posible invasión japonesa. Esta última, fue a causa de que Estados Unidos sospechaba que México le había cedido el istmo de Tehuantepec y Bahía Magdalena a Japón, así que a principios de 1911 comenzaron a circular rumores de que los nipones intentarían establecer una base militar en la costa occidental de México. Los estadounidenses se alarmaron porque de hacerlo así, en el istmo de Tehuantepec o Bahía Magdalena (ubicada a un poco más de 900 kilómetros de Ensenada pero en la misma península de Baja California) podría amenazar seriamente el eje comercial marítimo que trataban de establecer con la construcción del Canal de Panamá. Además, si una potencia extranjera se establecía en cualquiera de estos dos puntos, se ponía en riesgo la comunicación entre California y Panamá. También se mencionó que los japoneses estaban interesados en los puertos de Manzanillo, Salina Cruz y Ensenada; los primeros puertos por tener concesiones de pesca otorgadas por el gobierno mexicano en 1911 a pescadores japoneses, y se cree que se incluyó Ensenada para que fuera motivo de acción militar estadounidense con el fin de anexarse la península bajacaliforniana. Sin embargo, se comprobó que todos los rumores que inmiscuían a los japoneses fueron simplemente especulativos y falsos. ${ }^{19}$

Pasó poco más de un mes desde la toma de Mexicali para que las autoridades del centro del país enviaran ayuda para retomarla. El 6 de marzo arribaron a Ensenada los buques navales Guerrero y Demócrata. A bordo de ellos llegaron 500 hombres, cuatro ametralladoras y unas 150 mujeres que los acompañaban, para la preparación de alimentos. ${ }^{20}$ El buque Demócrata ya se había presentado años atrás en Ensenada, navegado en las costas cercanas a este puerto en los primeros años del siglo XX; condujo reemplazos de soldados a la Compañía Fija local y una escolta de 50 plazas para el batallón establecido en el Distrito Norte de la Baja California, así como otras actividades en la zona. ${ }^{21}$ Además, trajo parte del batallón de soldados que llegaron para combatir a los hombres que habían tomado Mexicali pero al desembarcarlos, partió del puerto quedando anclado solamente en Ensenada el Guerrero por varios meses en este

\footnotetext{
${ }^{19}$ Francis J. Manno y Richard Bednarcik. "El incidente de Bahía Magdalena”, Historia Mexicana, vol. 19, no. 3, (1970): 365.

${ }^{20}$ Samaniego, Nacionalismo y revolución: los acontecimientos de 1911 en Baja California, 401

${ }^{21}$ El Progresista, 3 de abril de 1904.
} 
lugar. El Guerrero, un buque naval de dos calderas, había sido construido en los astilleros Barrow de Liverpool, Inglaterra, lugar de donde navegó por el Atlántico hacia el Pacífico, con destino a Salina Cruz, haciendo escalas en las Islas Canarias, Pernambuco, Buenos Aires, Punta Arenas, Talcahuano y Callao hasta arribar a México el mes de noviembre de 1905. Estuvo al mando del capitán Manuel Azueta y llegó a contar con seis cañones Cannet de $100 \mathrm{~mm}^{22}$

Los soldados que arribaron al puerto ensenadense en estas embarcaciones formaron parte del Octavo Batallón comandando por el coronel Miguel Mayol pero, debido a la falta de paga y suministros, el batallón tardó semanas en salir desde Ensenada a Mexicali para enfrentarse a los revoltosos, que posteriormente el jefe político del Distrito llamó filibusteros.

Con el arribo del Octavo Batallón a Ensenada a bordo de los buques nacionales, la prensa californiana informó sobre la movilización de buques militares estadounidenses hacia Baja California y el 11 marzo de 1911, el diario Los Angeles Express reportó que el cañonero Princeton, localizado en Panamá, sería enviado hacia México y que el cañonero Yorktown navegaría desde San Diego hacia el sur con órdenes de llegar a varios puertos mexicanos. ${ }^{23}$ Además se especuló que el Yorktown llegaría primero a la península de Baja California para asegurarse que no había tropas japonesas en Bahía Magdalena. ${ }^{24}$

El Yorktown fue construido en Filadelfia, Pensilvania, Estados Unidos, en los astilleros William Cramp e hijos con cubierta de acero de doble tornillo y blindada. Su nombre deriva de un poblado de Virginia, Estados Unidos, en el cual se peleó una de las batallas más importantes de la guerra de independencia de ese país y fue la segunda embarcación militar de cuatro en portar el mismo nombre. Empezó a funcionar en la naval estadounidense a partir del 23 de abril de 1889 y se convirtió en uno de los cañoneros más activos de su época. Estuvo en campaña militar en Europa, Asia (principalmente en Japón y China) y en América, donde sirvió para dar protección a las

22 Manuel Ruiz Romero, "El primer combate aeronaval del mundo", en: http://www.mexicanaviationhistory.com/articulos/articulo.php?id=8

${ }^{23}$ Los Angeles Express, 11 de marzo de 1911.

${ }^{24}$ Samaniego, Nacionalismo y revolución: los acontecimientos de 1911 en Baja California, 300. 


\section{Francisco Alberto Núñez Tapia}

propiedades e inversiones estadounidenses en Nicaragua, Honduras y México. Estuvo dentro del escuadrón de la evolución, conocido como Escuadrón Blanco, el cual consistía de un gran número de embarcaciones militares estadounidenses que desempeñaron actividades de práctica militar en el Golfo de México, principalmente en Florida y Texas; y en la península de Baja California, en Bahía Magdalena, realizó más de cinco prácticas militares a finales del siglo XIX y principios del XX. ${ }^{25}$ Para 1911 se le comisionó como protector de las inversiones estadounidenses en México, principalmente en la costa del Pacífico y arribó por primera vez a Ensenada el 11 de marzo bajo órdenes del comodoro Richard T. Mulligan, quien se entrevistó con Celso Vega, el jefe del Distrito Norte. Los ensenadenses, aunque desconfiados por la presencia del buque militar estadounidense, no se alarmaron por encontrarse en el lugar el cañonero Guerrero ${ }^{26}$, pero supusieron que la aparición del Yorktown era con fines de espionaje.

En la prensa estadounidense se siguió especulando una posible invasión japonesa por Bahía Magdalena, y argumentaron que, de darse el caso de dicha incursión por parte de los nipones, contaba con más de cuatro mil soldados listos para repelerlos, y tres embarcaciones de combate: el Yorktown, el Truxtun y el Búfalo. El Truxtun, conocido en la marina estadounidense como el Truxtun II, torpedero destructor de barcos no. 14, fue otro buque militar extranjero que se encargó de la vigilancia y protección de las inversiones estadounidenses en Sudamérica y México. Aunque su principal campaña en este último país fue entre 1912 y 1916, en 1911 suplió varias veces al Yorktown en su recorrido como "guardacostas" en la península bajacaliforniana.

Varios reportes confirmaron la presencia del Truxtun en distintas partes de la península, sobre todo cerca de Bahía Magdalena lo cual produjo un sentimiento de amenaza a la población de Baja California, porque la prensa estadounidense remarcó

\footnotetext{
25 "Yorktown" Dictionary of American Naval Fighting Ships, en: https://www.history.navy.mil/research/histories/ship-histories/danfs/y/yorktown-ii.html

${ }^{26}$ De hecho, [...] el Guerrero, dio considerable protección contra cualquier posible invasor de la capital, que no tenía artillería. Sin embargo, al pueblo le faltaban tropas, y el jefe político no hizo nada por entrenar como soldados a los ciudadanos o por erigir baluartes contra un posible ataque relámpago. Displicente, desconfiado e indigno de confianza, Vega se encerró enfurruñado en la casa de gobierno. Blaisdell, La revolución del desierto Baja California, 1911, 160.
} 
mucho su poderío naval en el Pacífico y su posible utilización si fuera necesaria. La supuesta invasión japonesa la tomaron como posible excusa del gobierno de los Estados Unidos para invadir la península y unirse a los filibusteros.

Como anteriormente se mencionó, los estadounidenses e ingleses, poseían concesiones, inversiones y propiedades en México. Por ello, ambas naciones mandaron sus respectivos buques de guerra para que inspeccionar el movimiento armado en México y así salvaguardar sus inversiones. Pero mientras los buques estadounidenses realizaron su labor de "guardacostas" en Baja California, los ingleses enviaron al navío Shearwater para proteger sus propias inversiones en la península. Este buque militar inglés, de unas 980 toneladas, se construyó en la población de Sheerness, Inglaterra, contó con un motor de 1,400 caballos de fuerza de vapor vertical de triple expansión, cuatro calderas Belleville y portó 6 ametralladoras estacionarias de dos distintos calibres. Inició sus labores navales para dicha nación en 1900 navegado principalmente en las costas africanas y gran parte del Pacífico cuando fue llamado a inspeccionar el movimiento armado en Baja California. ${ }^{27}$ Esta embarcación era conocida por la población de Ensenada debido que su capitán en 1903 fue C.H. Umfreuille, hermano político de J.H. Packard, vicecónsul inglés con residencia en el puerto ensenadense y gerente de la Compañía del Desarrollo de la Baja California. ${ }^{28}$

El Shearwater ancló en San Quintín (poblado localizado al sur de Ensenada) entre finales de marzo y principios de abril de 1911 y su presencia desataría algunas semanas después de su arribo, un conflicto internacional, diplomáticamente hablando, porque no dio para más, cuando se rumoró que el buque inglés llevaría a cabo una invasión militar en suelo mexicano. Dicha embarcación llegó a San Quintín debido a los temores del gobierno británico de que la revuelta desatada en Baja California era un intento de anexión de la península a los Estados Unidos.

Debemos de recordar que en este periodo había contratos de concesiones a compañías de Inglaterra y Estados Unidos en gran parte del Distrito Norte de la Baja

\footnotetext{
${ }^{27}$ Rif Winfield y David Lyon, The Sail and Steam Navy List: All the Ships of the Royal Navy 1815-1889 (Londres, 2004), 278-279.

${ }^{28}$ El Progresista, 19 de abril de 1903.
} 


\section{Francisco Alberto Núñez Tapia}

California y, por ende, empleados de ambos países se encontraban en la región. Cuando inició el conflicto armado, y al reportarse que en algunos poblados y rancherías de Baja California se había atacado, de alguna u otra forma, a extranjeros, tanto los estadounidenses como ingleses temieron que sus propiedades fueran dañadas, saqueadas o destruidas.

Así que cuando se avistaron hombres armados en las cercanías del poblado de San Quintín, a principios de abril, gran parte de su población huyó mientras que los pocos comerciantes que se quedaron, de origen extranjero, acudieron a G.W. Vivian, comandante del Shearwater para que él, junto con sus marinos, los protegiera de cualquier atentado. Según Ramón B. Garza, uno de los agentes de la aduana local, no había amenaza de que los hombres armados entraran al poblado, pero, aun así, Federico R. Kearsy (inglés) y Henry Cannon (estadounidense), solicitaron al comandante Vivian que protegiera los intereses de los extranjeros en la península. El comandante del barco ordenó a su tripulación desembarcar junto con una ametralladora y defender el poblado, lo cual hicieron por unas 24 horas aproximadamente. Uno de los agentes aduanales trató de evitar el desembarcó, pero le fue imposible detener a 34 marinos ingleses. ${ }^{29}$

A continuación, transcribimos parte de la nota publicada el 16 de abril en el San Diego Union donde se describe lo sucedido en San Quintín:

Una fuerza de treinta y cuatro hombres y una ametralladora "Maxim" pertenecientes al barco de guerra inglés Shearwater, fueron desembarcados en San Quintín, México, con el fin de proteger dicha población de un ataque de los insurgentes. Los funcionarios del Departamento del Estado, dijeron [...] que el desembarque de la fuerza británica con motivo de las actuales dificultades y disturbios en México, no es un acto raro en lo que se refiere a las dificultades intestinas de los países de la América Latina. Declararon que muchos precedentes, podían añadirse a dicho acto del Shearwater. Sin embargo los insurgentes no se presentaron y los hombres y la ametralladora fueron reembarcados. Esto, que es el primer desembarque de fuerzas extranjeras, efectuado en México con motivo de la actual revolución, fue dado a

\footnotetext{
${ }^{29}$ Samaniego, Nacionalismo y revolución: los acontecimientos de 1911 en Baja California, 439.
} 
conocer al Departamento del Estado hoy, en un telegrama procedente del cónsul americano Schmucker, en Ensenada. [...] Cuando todo el peligro había pasado, en San Quintín, el Shearwater se hizo a la vela rumbo a Ensenada, donde [...] el Comandante notició al cónsul americano del acto del desembarque, llevado a cabo en San Quintín para la seguridad de la población. [...] El hecho de que treinta y cuatro marinos, a las órdenes del teniente Newcomb, del barco de guerra inglés Shearwater, desembarcaron en San Quintín, Baja California, el martes en la tarde, fue atestiguado por miembros de la tripulación de dicho barco, que llegó a este puerto hoy. [...] Ellos tomaron posesión de la población, colocaron una ametralladora Maxim, en el principal hotel, izaron la bandera inglesa en tres diferentes puntos del lugar y por veinte y cuatro horas estuvieron listos para repeler un ataque de los rebeldes. Prácticamente toda la gente del lugar se había retirado a los cerros inmediatos. Se cree que las fuerzas rebeldes forman parte de las de Berthold. Solamente dos ingleses y un americano permanecieron en la población. [...] Cuando los marinos regresaron a bordo del Shearwater el miércoles en la mañana, fueron llevados ahí los refugiados [...] y traídos a Ensenada [...] Dicho incidente ha sido dado conocer a Washington. El desembarque de fuerzas inglesas en San Quintín es el primer incidente de este género, ocurrido desde el desembarque similar llevado en Honduras, hace medio siglo. [...] "Si los rebeldes tenían en su plan atacar San Quintín, no se aparecieron mientras nuestros muchachos estaban en posesión del lugar”, dijo un miembro de la tripulación del Shearwater. El capitán Vivian no perdió tiempo en mandar a tierra fuerzas del buque, cuando supo que los ciudadanos americanos y los ingleses estaban en peligro. ${ }^{30}$

Los ingleses argumentaron que el desembarque no fue a causa de una invasión, sino de protección a ciudadanos ingleses, estadounidenses y mexicanos de ser atacados. Al arribar el buque inglés a Ensenada y conocerse sobre el desembarque de marinos ingleses, la jefatura local envió un oficio al capitán Vivian donde se le exigía una explicación de dicho acto en el puerto de San Quintín, ya que no contaba con la

\footnotetext{
${ }^{30}$ Informe de Ramón Barberena Garza, jefe de la sección aduanera de San Quintín y de Feliciano Aldrete Palacio, subjefe de la misma; sobre ataques rebeldes y el desembarque de tropas inglesas en dicho puerto para proteger a la población, 1911, en Acervo Documental del Instituto de Investigaciones Históricas de la Universidad Autónoma de Baja California, Colección Adalberto Walther Meade, caja 6, exp. 4 ref. 6.4.
} 


\section{Francisco Alberto Núñez Tapia}

autorización necesaria para realizar cualquier actividad militar en la región. Antes de tener respuesta inmediata, el Shearwater zarpó rumbo San Diego, de donde Vivian contestó al jefe del Distrito lo solicitado:

Como Ud. sabe, las comunicaciones entre Ensenada y San Quintín estaban interrumpidas [...] y los empleados federales en San Quintín, habían abandonado la población el día antes de mi desembarque, al saber que los rebeldes se aproximaban. El hecho de que dichos empleados abandonasen la población, prueba por sí solo, que dichos Señores se anticiparon a un peligro y disturbios contra cuales no podían lidiar. En caso de que dichos empleados hubiesen permanecido en la población, no hubiera yo pensado desembarcar una partida de gente sin haber pedido antes su autorización, pero en vista del hecho de que ellos habían salido del lugar y de que yo recibí una petición por escrito en la que se me pedía protegiera los intereses, vidas y demás propiedades de los súbditos ingleses, los cuales indudablemente estaban en peligro, consideré propio tomar los pasos y medidas que en mi opinión creí necesarios para atender dicha petición. Debo añadir que dos empleados del Gobierno mexicano, los señores R. B. Garza y F. A. Palacio, solicitaron y obtuvieron protección, y fueron traídos a Ensenada, a petición suya, a bordo del barco de su Majestad. ${ }^{31}$

Como se aprecia en la respuesta de Vivian el propósito del desembarco de los marinos fue con el fin de proteger las inversiones inglesas que se le habían encomendado desde un principio. A su vez, se entiende su salida rápida de Ensenada antes de dar esta noticia al jefe del Distrito Norte, ya que temía que, al no contar con la autorización debida, ocasionaría un conflicto entre ambas naciones.

La prensa estadounidense por su parte, elogió los hechos del capitán Vivian y la tripulación del Shearwater.

La manera en que fue desembarcada la fuerza inglesa, en San Quintín para proteger a los ciudadanos ingleses, y a los demás extranjeros, ha causado admiración y un poco de envidia entre la gente americana. [...] Este es el modo Inglés, y hablando generalmente, es un buen modo. [...] El incidente en San Quintín, indica claramente lo

\footnotetext{
31 Acervo Documental del Instituto de Investigaciones Históricas de la Universidad Autónoma de Baja California, Colección Adalberto Walther Meade, caja 6, exp. 4 ref. 6.4.
} 
que Gran Bretaña haría en igualdad de circunstancias, la gente y las propiedades deben de ser protegidas primero y la diplomacia [...] en segundo término. ${ }^{32}$

Los estadounidenses admiraron el despliegue militar inglés en San Quintín debido a que el gobierno de Estados Unidos tenía, apostados en la línea fronteriza con el Distrito Norte de Baja California, tropas militares las cuales no actuaron en el territorio mexicano, ante la inconformidad de las personas residentes de ambos lados de la frontera, pero no lo hicieron para no ocasionar otro conflicto armado entre México y Estados Unidos.

Finalizado este incidente y debido a que la población de Tijuana (ubicada al norte de Ensenada) fue ocupada en el mes de mayo por los mismos hombres que habían tomado Mexicali, gran parte de la población ensenadense huyó vía marítima rumbo a San Diego para refugiarse de un posible ataque contra la población. El hecho de que Tijuana fuese tomada, aseguró en la mente de los ensenadenses, que el puerto sería el próximo en caer, por lo cual decidieron, en su mayoría, huir de la capital del Distrito Norte. Hubo el caso hasta de una familia que rentó un barco de San Diego para que fuera exclusivamente por ellos y los trasladara a California. ${ }^{33}$

La retirada de los ensenadenses fue contraria al acto de defensa improvisada llevada a cabo el 28 de febrero y se suscitó debido a la ocupación de Tijuana, hecho que produjo la retirada del puerto. Cabe resaltar, de forma irónica, que huyeron hacia San Diego, lugar de donde meses antes se especuló que saldría una fuerza de filibusteros estadounidenses que tomarían Ensenada.

El 13 de mayo de 1911 más de 140 ensenadenses desembarcaron en San Diego, entre ellos Manuel Labastida, presidente municipal de Ensenada, al cual se le despojaría de dicho cargo por el disgusto ciudadano de no haberse quedado a defender la población meses después de este suceso. En San Diego, Labastida, como otros ensenadenses, se unieron a la junta organizadora llamada Defensores de la Integridad Nacional, formada por mexicanos que vivían en San Diego y realizaron distintas actividades para reclutar a

\footnotetext{
32 Acervo Documental del Instituto de Investigaciones Históricas de la Universidad Autónoma de Baja California, Colección Adalberto Walther Meade, caja 6, exp. 4 ref. 6.4.

${ }^{33}$ Samaniego, Nacionalismo y revolución, 2008, 522.
} 


\section{Francisco Alberto Núñez Tapia}

hombres para que fueran a defender Ensenada de un posible ataque. Para lograr su cometido, los Defensores de la Integridad Nacional publicaron una nota en la prensa sandieguina, el 17 de mayo, donde exaltaban a los mexicanos a unírseles:

\section{Mexicanos:}

En estos momentos en que la integridad nacional peligra, la Patria reclama los servicios de sus leales hijos para defender su honor mancillado por una turba de bandidos extranjeros, que van sembrando el luto y la desolación en los pueblecitos de la Baja California. Sin ningún espíritu de partido, convocamos al pueblo mexicano de esta ciudad y de sus alrededores, porque es deber nuestro ofrendar nuestras vidas, si necesario fuese, para castigar a los bandoleros que en aciaga hora tratan de disgregar esa porción del territorio nacional, aprovechando las circunstancias aflictivas porque atraviesa el país. ¿Permaneceremos indiferentes ante tamaña infamia? ¿No sentimos arder la indignación en nuestro pecho y ansia por combatir contra las hordas filibusteras que tan descaradamente se alaban de sus triunfos y se burlan de nuestra timidez y apatía? ¡Compatriotas alerta! ¡A las armas!

No olvidéis que descendemos de una raza de héroes que han preferido mil veces la muerte a la esclavitud. ${ }^{34}$

Al parecer su proclamación fue todo un éxito ya que reunieron suficientes voluntarios los cuales arribaron a Ensenada vía marítima. La llegada de estos hombres tranquilizó a la población que se había quedado a luchar y al jefe político, pero Vega descansó más al saber que el coronel Mayol regresaba de Mexicali. Al llegar Mayol a Ensenada, Vega tomó el mando del Octavo Batallón de infantería y la Compañía Fija del Distrito que, junto con los voluntarios llegados de San Diego y residentes del puerto y otros lugares de Baja California, sumaron unos 800 hombres aproximadamente. ${ }^{35}$ Con ellos, Vega avanzó sobre Tijuana y retomó el poblado el 22 de junio de 1911. Derrotado el movimiento armado que había iniciado en enero en Mexicali y a los pocos meses de haber finalizado el conflicto, los voluntarios que habían llegado desde San Diego se retiraron de Ensenada y el Guerrero, que por haber estar anclado en el puerto en los meses que duró el conflicto y resguardó al mismo de un posible ataque por temerle a su artillería, zarpó rumbo al Golfo de México. No obstante, los buques estadounidenses

\footnotetext{
${ }^{34}$ San Diego Union, 17 de mayo de 1911, tomado de: Samaniego, Nacionalismo y revolución, 2008, 524.

35 San Diego Union, 17 de mayo de 1911, tomado de: Samaniego, Nacionalismo... 523 y 529.
} 
Yorktown y Truxtun siguieron su vigilancia en la costa oeste del Pacífico mexicano sin llegar a causar un incidente diplomático como lo hizo el Shearwater.

\section{Conclusiones}

Los buques de guerra tuvieron mediano impacto en Baja California en la transición de los siglos XIX-XX. Por medio de estos se transportaron filibusteros como fue en el caso de Walker en 1853 a bordo del Carolina, y aunque esta embarcación solo sirvió como navío de transporte, generó temores de que las futuras invasiones extranjeras serían venidas con respaldo de los navíos de guerra. Para 1890 se incrementaron la presencia de los buques por haber una numerosa población extranjera en la península, radicados la mayoría de ellos en la cabecera del Distrito Norte de la Baja California ubicada en Ensenada de Todos Santos. Al estar semi-rodeada por agua, el puerto resultaba un lugar predilecto al tener un amplio espacio geográfico donde podrían desembarcar tropas filibusteras y tomar a la población desprevenida, como se dio el caso en 1853 y se especuló en 1890. La salida y conexión marítima con California, que daría la toma de Ensenada a los filibusteros, sería para establecer líneas de suministros, provisiones y hombres para llevar a cabo sus campañas y por eso la captura del puerto siempre fue pensada para tener éxito.

El temor de una invasión rápida llegada por la vía marítima, fue una constante para los bajacalifornianos, en especial los residentes de Ensenada. Es por ello que en febrero de 1911 armaron una defensa improvisada por defender el puerto, tanto de los filibusteros que habían tomado Mexicali, como de cualquier embarcación extranjera que arribara al puerto. Un dato que no podemos obviar es que aunque los filibusteros de 1911 pretendieron tomar Ensenada para tener una vía rápida de comunicación con el exterior, suponemos no lo hicieron por estar en el puerto anclado el Guerrero, el cual era temido por su artillería. Al igual que en 1853, cuando Walker decide retirarse de Ensenada y la costa por pensar que un buque mexicano podía llegar a capturarlo, el Guerrero en 1911 sirvió para frustrar cualquier ataque marítimo a la cabecera del 


\section{Francisco Alberto Núñez Tapia}

Distrito Norte, por lo cual los filibusteros optaron por tomar Tijuana. Aun con el buque mexicano anclado en el puerto muchos de los residentes de Ensenada, al enterarse de la toma de Tijuana en mayo, y al saber que los estadounidenses poseían varios buques militares que recorrían constantemente la zona, optaron por huir hacia San Diego, de donde armaron un movimiento armado para resguardar Ensenada y retomar Tijuana. Pero la realidad fue que la presencia de estos buques durante los conflictos armados, sobre todo los de 1911, generaron estabilidad en la región ya que hasta cierto punto evitaron batallas y destrucción de propiedades.

Es por ello que se debe de hacer un estudio más exhaustivo del papel de los distintos navíos que tuvieron contacto con la península de Baja California, ya que, al estudiar los movimientos marítimos de los buques militares, pero también comerciales y turísticos que propiciaron el crecimiento demográfico de la península, se podrá tener un mejor conocimiento del grado en que moldearon el desarrollo económico y social de la entidad al estudiar su desempeño dentro de la historia marítima bajacaliforniana.



\section{FUENTES}

Acervo Documental del Instituto de Investigaciones Históricas de la Universidad Autónoma de Baja California, Colección Adalberto Walther Meade.

\section{BIBLIOGRAFÍA}

Blaisdell, Lowell L. La revolución del desierto Baja California, 1911. México: Universidad Autónoma de Baja California, 2005. 
Busto Ibarra, Karina. El espacio del Pacífico mexicano: puertos, rutas, navegación y redes comerciales, 1848-1927. Tesis doctoral. México: El Colegio de México, 2008.

Heath Constable, Hilarie J. "La época de las grandes concesiones, 1883-1910". En Catalina Velázquez Morales (coord.) Baja California, un presente con historia. UABC. Tijuana, 2002. (Tomo I).

León-Portilla, Miguel y José María Muría (comps.) Documentos para la Historia de Baja California, siglo XIX. Tomo I. Fundación Manuel Arango, México, 2009.

Littlehales, G.W. The methods and results of the survey of the west coast of Lower California by the officers of the "U.S.S. Ranger" during the season of 1889 and 1890. Washington, 1892.

Manno, Francis J. y Richard Bednarcik. "El incidente de Bahía Magdalena", Historia Mexicana, vol. XIX, núm. 3, enero-marzo 1970.

Manno, Francis J. y Richard Bednarcik. "El incidente de Bahía Magdalena”, Historia Mexicana, vol. XIX, núm. 3, enero-marzo 1970.

Moyano Pahissa, Ángela. "La invasión del filibustero William Walker", en David Piñera Ramírez (coord.) Panorama Histórico de Baja California, Universidad Autónoma de Baja California, Tijuana, 1983.

Núñez Tapia, Francisco Alberto. "La industria del transporte marítimo y terrestre y el mercado fronterizo en el noroeste de la península de Baja California, 18821928”, en Álvarez Palma, Ilse Angélica (coord.), Automotores y transporte público. Un acercamiento desde los estudios históricos. El Colegio Mexiquense, A.C., Zinacantepec, Estado de México, 2017.

Piñera Ramírez, David. “Las compañías colonizadoras en Ensenada, 1886-1910” en Ensenada: Nuevas aportaciones para su historia. Universidad Autónoma de Baja California, Mexicali, 1999.

Ruiz, María Jesús. “Aspectos económicos en el Partido Norte, 1849-1888” en Catalina Velázquez Morales (coord.) Baja California, un presente con historia. UABC. Tijuana, 2002. (Tomo I). 


\section{Francisco Alberto Núñez Tapia}

Ruiz, María Jesús. Documentos para la Historia de Baja California, siglo XIX. Tomo II. Fundación Manuel Arango, México, 2009.

Samaniego López, Marco Antonio. Nacionalismo y revolución: los acontecimientos de 1911 en Baja California, Tijuana, Universidad Autónoma de Baja California, 2008.

Valadez, Adrián. Antonio Melendres. Reedición del Museo de Historia de Ensenada y la Sociedad de la Antigua California. Ensenada, 2015.

Winfield, Rif y David Lyon. The Sail and Steam Navy List: All the Ships of the Royal Navy 1815-1889. Londres, 2004.

\section{Hemerografía}

Daily Alta California

El Progresista

Los Angeles Express

San Diego Sun

San Diego Union

Sitios web

https://www.history.navy.mil/research/histories/ship-histories/danfs/y/yorktown-ii.html http://www.mexicanaviationhistory.com/articulos/articulo.php?id=8 